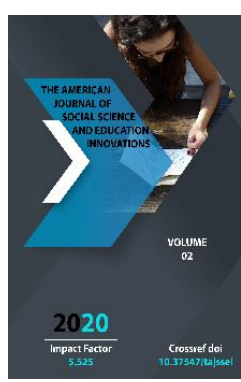

Copyright: Original content from this work may be used under the terms of the creative commons attributes 4.0 licence.

\section{Model Of Diagnostics And Improvement Of Quality Of Preparation For Professional Activity Based On Integration Of Pedagogical And Technical Knowledge}

\author{
Jumanov Alisher Asatullayevich \\ Basic Doctoral Student, Tashkent Institute Of Irrigation And Mechanization Of Agriculture, \\ Tashkent, Uzbekistan
}

\author{
Ibragimova Gulzoda Nabievna \\ Assistant, Tashkent Institute Of Irrigation And Mechanization Of Agriculture, Tashkent, \\ Uzbekistan
}

\author{
Abduraxmonova Shohidaxon Abduqodirovna \\ Assistant, Tashkent Institute Of Irrigation And Mechanization Of Agriculture, Tashkent, \\ Uzbekistan
}

\title{
ABSTRACT
}

In this article the model of diagnostics and improvement of quality of preparation for professional activity on the basis of integration of pedagogical and technical knowledge and its contents are described. Expert model is a standard description that provides successful solutions to emerging problems in the manufacturing industry, defines certain qualities and reflects the professional knowledge and self-development of a professional, and is one of the types of qualifications that are specific to each position and job. professional activities, tasks and responsibilities, personal qualities, knowledge and skills.

\section{KEYWORDS}

Integration, pedagogical and technical knowledge, modeling, modeling, expert model, professional description, component, diagnostics.

\section{INTRODUCTION}

The need to address the problem of teaching teachers in the diagnosis of vocational training as a result of the integration of pedagogical and technical knowledge is determined by the professional activity of the teacher of vocational training.
In terms of structure, the expert model should include components that allow it to be modified and corrected, which influences the effectiveness of the operation and can be easily diagnosed. An expert model with a twopart structure is the most common model [9]. 


\section{MATERIAL AND METHODS}

Expert model is a standard that provides successful solution of emerging problems in the manufacturing industry, defines certain qualities, and reflects the knowledge and selfdevelopment of the professional.

In creating this model, a set of personal qualities suitable for a particular type of professional activity is regulated.

One of the types of expert models is qualifications. The content reflects the following: types of professional activities, tasks and responsibilities, personal qualities, knowledge and skills typical for each position and job. Such models are important in the selection and placement of personnel, their attestation, as well as the development of specialist training and retraining programs.

Qualification descriptions are also called normative models. This is a special passport that reflects the general requirements of the specialist and his / her personality.

\section{RESULTS AND DISCUSSION}

Integrative and practical data on qualification characteristics have been identified by E.M.Borisova [2]. According to the author, the structure of qualifications is as follows:

1. Personal Features.

2. The main activities and types.

3. Types of organizations in which they operate.

4. Positions that they can hold.

5. Requirements for personal qualities.

6. Professional Qualification Requirements.

7. The order of duties performed on the position.

8. Requirements to the level of professional knowledge.

9. Diagnose the process of preparation for professional activity

10. Professional competence of the student
11. Integrated approach to professional activity

One of the objectives of our research is to create diagnostic conditions for integration of pedagogical and technical knowledge, based on which monitoring of teachers' professional activity [5].

Principles of modeling specialist activity in the learning process. Modeling is a scientific method that allows you to create different models of the subject of knowledge and use it in scientific creativity. In the modeling method, instead of an object, its model is studied.

Modeling is to work or create a model of something.

Modeling in the teaching activity on the scientific basis of education, the modern requirements for the educational process (independent education, upbringing, selfeducation) and its implementation, student needs, students' worldviews and initial understanding, tasks for students, opportunities for independent learning Take into account the purpose, subject and importance of the taught subject and subjects studied, and the selection of appropriate teaching methods, the tasks that need to be accomplished, and and the implementation steps. To prove content and goals through modeling, first acquire easy knowledge, select teaching methods based on curriculum and curriculum requirements. A wide range of activities in the learning process is provided on the following conditions:

a) Polytechnic orientation of knowledge and skills.

b) The role of gradation in the integration education.

c) The transfer process.

Despite the differences in approaches to modeling the personality and activities of the specialist, the research has not investigated 
the problem of the professional and personal development of the specialist in the system of vocational training, as well as the model of the professional training process of the specialist. M. Rosenberg, a British scientist, has developed nine areas of teaching and the following professional requirements:

- Knowledge of students' needs and needs;

- Ability to evaluate performance;

- Ability to design curricula;

- Professional skills;

- Be a consultant;

- Be able to communicate;

- Ability to conduct research;

- Continuous improvement of professional skills;

- Achievement of cultural identity of the person.

S.I. Arhangelsky considers modeling as a particular method of dating, based on the principle of material unity in the world and the existence of the living and inanimate nature of common dialectic laws of universal development, the identification of universal connection and phenomena [1].

In the most general sense, the model is a specially created object that needs to be recognized.

Currently, modeling using specialized devices in scientific research has become an important way of scientific knowledge and is used to study the specific, peculiarities of the object of study.

G. Klaus describes modeling as a reflection of the facts, objects, and relationships of a particular field of knowledge in the form of a simplified and visible material structure of this or that area.

Thus, modeling requires calculations, observations, logical analysis of models, so the results of such studies can be used to identify events that occur in real things.
According to the theory of similarity, some conditions are required for modeling.

1. Similar phenomena occur in similar systems and can be expressed by the same mathematical or logical dependencies. These dependencies must be identical or conditional.

2. When two or more sets of elements are aligned, and the change of one set element corresponds to the change of the other set of elements.

3. Modeling considers that such objects and events have the same number of similarity criteria.

4. The condition of similarity is the generality and equality of similarity criteria.

5. Material modeling from the relationship between the qualitative and quantitative features of the studied object [1, pp. 72-73].

The use of similarity techniques to describe the learning process is of great interest, as each teacher creates a subject that is always understood - either unclear or directly - when learning their subject or learning. In addition, the teacher is concerned with the construction of various schemes, tools, methods, programs for the use of teaching forms [3].

Such modeling is not sufficient for modern scientific research, as it does not require a subjective but objective description of the relationship between the study of an object and its cognitive process in the first place [1].

Activity is, in general, an ad-hoc activity based on the interaction of live systems with the external environment. When it comes to human activities, it can be defined as a socially oriented activity of people. And adaptation is just one way of doing that. Indeed, any professional-pedagogical adaptation requires activity, be it social activity or individual activity, but it is interpreted as professional pedagogical adaptation, not any activity, but a positive change in the social, economic, and spiritual spheres of society. It is advisable to do 
so. Activities as a way of developing professional adaptation primarily involve spiritual, professional and creative activities. Cultural skills are created during this activity. The standards of professional activity can be a special transmitter of worldviews. In our view, the norms of professional activity and adaptation are a reflection of the professionalism of the profession and the way in which it is shaped by the interaction between the norms of professional activity and the norms of professional thinking. The Expert Model is a reflection of curricula, programs, and other documents that regulate the process of training specialists in higher education. That is, the most general model of a professional training model is a schematic representation of the socio-political, organizational and managerial, ethical knowledge of the characteristics, volume and structure of skills required for labor activity, and provides the following:

- Functional formation of the specialist;

- The breadth of the profession;

- Professor description;

- Schemes of academic disciplines, taking into account their size and proportion.

Here, he believes, the best curriculum can be built on the basis of the student model that needs to be developed as a customer, taking into account the requirements of the specialist. There are other supporters. They incorporate expert knowledge, skills, and so on in the concept of an expert model. In our view, the teacher training model is not a coherent concept involving curriculum, curricula, or other documentation, as it serves to unveil the qualities that form the basis of a future teacher's professional work. Creating a model of specialist pedagogical activity is a complex and multifaceted task, with the following steps:

- To identify the main parameters of the expert model in the form of hypotheses and then at the research level.
- Selection, design, standardization of model parameters for design;

- Development of methodological bases for creation of expert model.

M. Ochilov introduces the following as a model of training for a future teacher or specialist: the object studied is his individuality; change of the personality of the student starting from the first year, depending on the process of professional orientation and preparation of the object; integrated learning system - specialist training system; the exact meaning of the model - the formation of the individual in the course of vocational training from the first year of study; a clear suggestion of the processes of personality formation that depend on the developmental context and experience of the teacher; method of definition - quality, phenomenon level, based on experience of teacher of higher education institution; The main tool is the professional orientation of the educational process.

The mechanism of improvement of professional competence of students is the basis for integration of pedagogical and technical knowledge in diagnostics of preparation for professional activity. On the basis of this, based on the development of a training model for the professional education teacher to diagnose their professional activities, their professional activity as a diagnostic object should be integrated into the objective and operational aspects of student learning. The unity of educational activities and the structure of vocational-pedagogical activity provides for integration of pedagogical and technical knowledge in the process of diagnostics of vocational training teachers for professional activity.

The operational aspect of learning activities differs from the level of generalization of knowledge and instruction: special skills and abilities, the normalization of educational activities within the subject; the guiding principles of the movement; way of knowing 
activities. Knowledge of the sciences directly determines the meaningful aspect of pedagogical and technical learning activities. In the process of preparing teachers for vocational training, there is an internal link between these two components because of the nature of their professional activities [4].

The process of diagnosing future training for professional activities should be multi-step such an approach will help to form the necessary knowledge system and then integrate the acquired knowledge (vocational training) [7].

Thus, one of the tools and means of acquiring pedagogical knowledge for students is to change the scope of their professional activities in the future.

As a result of the research work, a model of training and diagnosing the results of future professional education teachers for professional activity based on the integration of pedagogical and technical knowledge was developed based on practical pedagogical experience (Figure 1).

The model of training and diagnostics of future professional education teachers is a model that provides successful solution to emerging problems in the field of professional activity, characterizing certain qualities of an expert, and reflects self-knowledge and selfdevelopment and learning outcomes. Based on the model structure, it is necessary to initially develop the content of vocational training based on an integrated approach, information, reproductive, heuristic, research, integrative, problem presentation, pedagogical diagnostics, integrated lectures, case studies, independent work; Organizational aspects of individual (individual) work, research, continuity, sequence, demonstration, activity, mobility, interdisciplinary communication were studied [6]. 


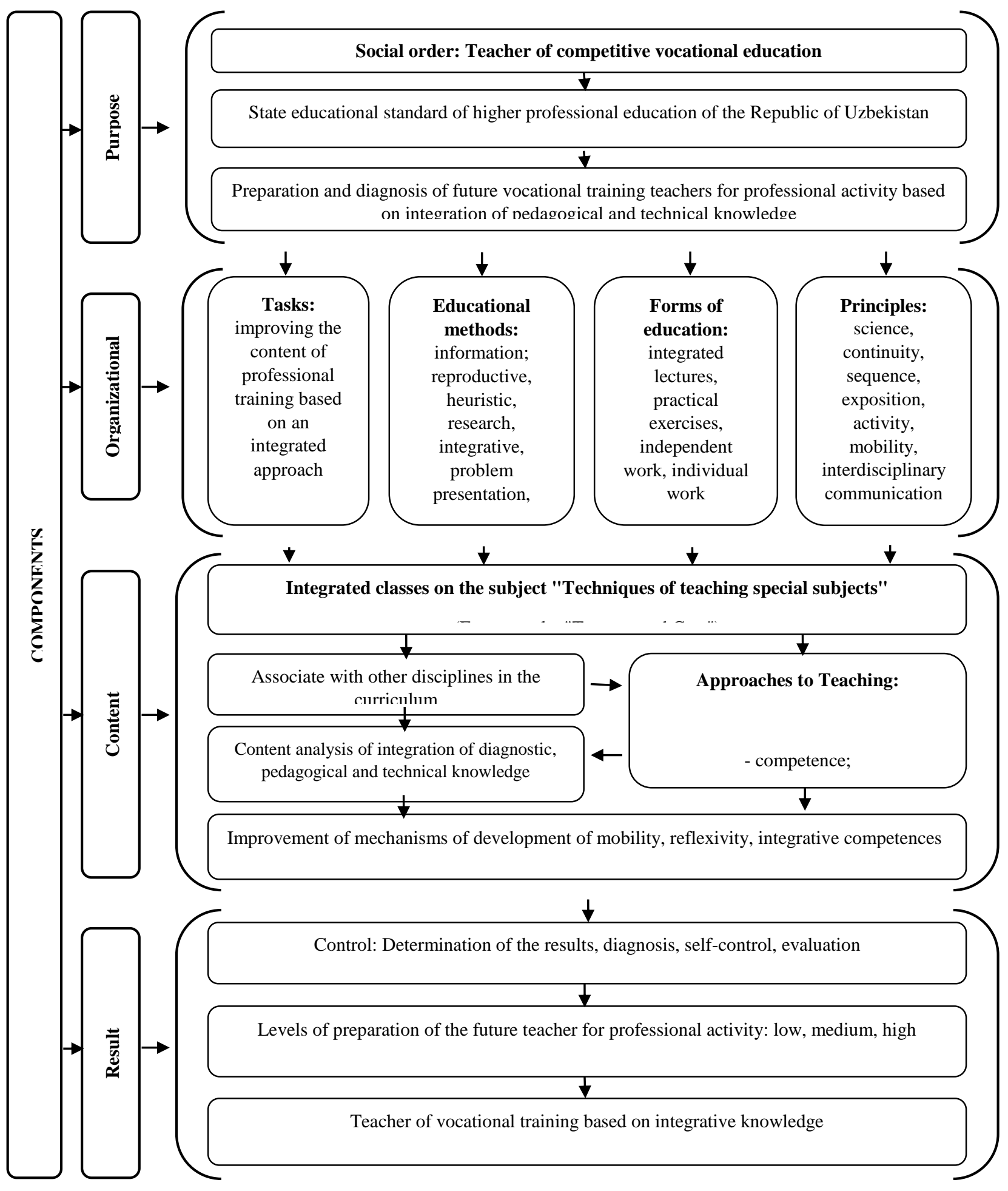

Figure 1. Model of preparation and diagnostics of professional activity on the basis of integration of pedagogical and technical knowledge 
Purpose Component of Integrated Education Model (preparation of the future teacher of professional education in accordance with the state educational standards of the Republic of Uzbekistan on the basis of social order for the teacher of competitive vocational education and diagnostics of professional activity based on the integration of pedagogical and technical knowledge), definition and development of educational forms and principles of education), content component ("Methods of teaching special subjects") and the development of mobility, reflexivity, integrative competence in future vocational education teachers through the use of competency-based, integrative, diagnostic approaches based on programs developed by Tractors and Automobiles, and a component of results (based on pedagogical and technical knowledge of future vocational education teachers). diagnostics of readiness for professional activity).

The process of developing students' professional skills was accomplished through various tasks. Four levels of professional and pedagogical skills (intuitive, reproductive, reproductive-creative, creative) are defined depending on the nature of the activities performed.

The mechanism of development of competencies such as mobility, reflexivity, integrability in theoretical, practical, and professional training areas has been improved on the basis of classification of important personal qualities and skills of future specialists.

\section{CONCLUSIONS}

The model developed based on the principle of integrality, as well as evaluation criteria for determining the level of professional skills in preparation for professional activities. Methods of pedagogical diagnostics of professional education teachers' professional activity (specific analysis, intensive training, problem situation, non-standard testing) have been improved by setting expert evaluation criteria and systematizing their organizational and functional capabilities such as objectivity, integration, feedback, psychological adaptation.

\section{REFERENCES}

1. Arkhangelsk S.I. The educational process in higher education, its regular principles and methods. - M., 1980 .- 191 p.

2. Borisova E.M. Professional selfdetermination: personal aspect.: Author. diss.... doc. psychol. sciences. - M., 1995 -- 41 p.

3. Ismailova ZK Formation of students' professional pedagogical skills: Diss. ... ped. science. Candidate - T.: 2000. - 186 b.

4. Muslimov N.A. Theoretical-methodological bases of professional formation of teacher of vocational education. Diss... ped. f. d. - T.: 2007. - 315 b.

5. Khimmataliev DA, Baybaeva $\mathrm{MH}$, Farhutdinova $M$. The use of innovative educational technologies to modernize the educational process of the vocational education system: a methodological handbook. - T.: TIMI, 2015. - 98 p.

6. Khimmataliev D.O. Formation of professional competence of future vocational education teachers in technical higher education institutions through interdisciplinary integration // llim de jamiet (Science and Society). -Nukus, 2017. No.1. B.54-56. (13.00.00; No. 3).

7. Khimmataliev D.O. Integration of scientific knowledge in preparation for the professional activities of future teachers of vocational education // School of the future. Moscow, 2016. No. 6. -S. 50-54. (13.00.00; No. 20).

8. Khimmataliev D.O. The essence of the concept of integration and interdisciplinary communication // Vocational education. Tashkent, 2016. №6. -B.13-16. (13.00.00; No. 19).

9. Khimmataliev D.O. Integration of pedagogical and technical knowledge in the 
The American Journal of Social Science and Education Innovations (ISSN - 2689-100x)

Published: December 18, 2020 | Pages: 107-114

Doi: https://doi.org/10.37547/tajssei/Volumeo2Issue12-19

preparation of professional activities. Monograph. - Tashkent: Uzbekistan, 2018. $168 \mathrm{p}$.
10. Khutorskoy, A.V. Key competencies as a component of a personality-oriented paradigm [Text] / A.V. Khutorskoy // Public Education. - 2003. - No. 2. - S. 58-64. 